\title{
LOS RUINOSOS PILARES DEL PROGRESO
}

\author{
Antón FERNÁNDEZ DE ROTA IRIMIA \\ Universidade da Coruña
}

\begin{abstract}
RESUMEN: La concepción ilustrada del progreso ha sido largamente criticada desde la antropología y el resto de las ciencias sociales. Este artículo vuelve sobre esta crítica. Retoma, en un primer momento, la deconstrucción del "progreso" a través de la comparativa con las sociedades forrajeras largamente estudiadas por los antropólogos y plantea, en un segundo momento, una crítica más allá de las aproximaciones del evolucionismo social a través de las interpretaciones de la "historia" de distintos autores postestructuralistas.
\end{abstract}

PALABRAS CLAVE: progreso, antropología, historia, cultura occidental, deseo.

ABSTRACT: The illustrated conception of progress has been criticized for a long time by the anthropologists and the rest of the social sciences. This article returns on this critique, recapturing, in a first moment, the deconstruction of "progress" through the comparation with hunter-gatherers societies studied by the anthropologists and raising, in a second moment, a critique beyond the social evolutionist approximations through the interpretations of different poststructuralists authors about "history".

KEYWORDS: progress, anthropology, history, western culture, desire.

Hasta los años 60 aún era mayoritario en la antropología un triste paradigma sobre la vida de ciertas sociedades "sin estado" que llamaba "primitivas". Se trataba de una visión altamente complaciente con la idea ilustrada del Progreso y el ethos capitalista. La aceptación de la famosa proclama hobbesiana al respecto de la vida "salvaje"- "brutal, sucia, desagradable, pobre y corta"- dibujaba a menudo un panorama de terror y necesidad al borde de la inanición que legitimaba los distintos avatares imperialistas. El mito romántico rosseauniano, paternalista, solía funcionar de una manera análoga desde el anverso. Por supuesto, ya desde los propios orígenes de la antropología algunos etnógrafos se habían desmarcado de este tipo de planteamientos. Tal fue el caso de Franz Boas y su militante antirracismo, o Marcel Mauss y su formulación anticapitalista de la defensa de la alteridad. No obstante, la década de los 1960 marcó un punto de inflexión, una verdadera revolución dentro de la antropología, una revolución que radicalizó y generalizó la 
crítica al etnocentrismo y allanó los ulteriores avatares "reflexivos" y comprometidos de la disciplina.

A partir de los distintos trabajos etnográficos sobre las sociedades cazadorasrecolectoras, especialmente tras el congreso antropológico "Man the Hunter" (Chicago, 1966), se intentó desmontar el triste panorama de la "naturaleza humana", justo en el momento en que eclosionaban las teorías y las luchas contra el colonialismo y se iniciaba la crítica radical y sistemática de la propia noción renacentista e ilustrada de la universal naturaleza humana. Esta inflexión acontecía después de las primeras grandes catástrofes occidentales.

A lo largo del siglo XX, especialmente tras los traumáticos horrores producidos por Occidente -las dos guerras mundiales, el holocausto nazi, la amenaza nuclear-, no cesaron de proliferar durante décadas las críticas al progreso, así como al autocomplaciente occidentalismo implícito. Del optimista triunfalismo de la época victoriana se pasó con estos dramáticos acontecimientos a una fría tristeza, incluso al rechazo en el ámbito académico y no sólo académico de la idea progresista, denunciada ahora como mitología burguesa. Y así, por ejemplo, "cepillando la historia a contrapelo", muy con el espíritu del tiempo, Walter Benjamin, en sus Tesis sobre la filosofía de la historia, transmutaría los términos definiendo el "progreso" como catástrofe. En su conocida tesis novena, a propósito del Angelus Novus de Klee, escribe:

"En él vemos a un ángel que parece estar alejándose de algo mientras lo mira con fijeza. Tiene los ojos desorbitados, la boca abierta y las alas desplegadas. Ése es el aspecto que debe mostrar necesariamente el ángel de la historia. Su rostro está vuelto hacia el pasado. Donde se nos presenta una cadena de acontecimientos, él no ve sino una sola y única catástrofe, que no deja de amontonar ruinas sobre ruinas y las arroja a sus pies. Querría demorarse, despertar a los muertos y reparar lo destruido. Pero desde el Paraíso sopla una tempestad que se ha aferrado a sus alas, tan fuerte que ya no puede cerrarlas. La tempestad lo empuja irresistiblemente hacia el futuro, al cual da la espalda, mientras que frente a él las ruinas se acumulan hasta el cielo. Esa tempestad es lo que llamamos progreso".

\footnotetext{
${ }^{1}$ LöwY, Michael (2002): Walter Benjamin. Aviso de incendio. Buenos Aires: Fondo de Cultura Económica, p. 100.
} 
En muy distintas sociedades y épocas ha estado presente la idea del perfeccionamiento, del devenir temporal como una acumulación de mejoras en las infraestructuras o en los saberes. ${ }^{2}$ No obstante, la moderna idea de progreso que aquí nos interesa no empezó a forjarse hasta finales del siglo XVII, con el pensamiento de personas como Bernard de Fontenelle. Tal idea concebía una suerte de razón teleológica, en la cual la humanidad avanzaba a lo largo del tiempo hacia una mayor perfección, medida esta según los valores de una weltanschauung concreta que a partir del Renacimiento comenzaba a articularse: el occidentalismo. Lo cierto es que hasta tal fecha, lo más habitual había sido pensar las cosas al modo contrario; el conocido "siempre tiempos pasados fueron mejores", ya se ubicase el tiempo idealizado en el Edén o en los clásicos. La revolución científica del siglo $\mathrm{XVI}$, el hecho de haber superado en astronomía a los propios griegos, las innovaciones de Newton, Keplen o Galileo, ayudaron a que emergiera una nueva visión fervientemente optimista que pasaría a ser un principio axiomático, incluso axial, en la ideología de la Ilustración, de Kant a Condorcet. La ideología del Progreso rápidamente se hibridó con los flujos capitalísticos deviniendo una ideología única y total que en el siglo XIX se engarzaría con las teorías evolucionistas para dar una explicación igualmente total y universal de la historia.

La ideología del progreso hermanó tempranamente con los afanes de la industrialización e impulso a los industriales a emprender la colosal tarea del hierro, el carbón y el vapor. La idea ilustrada de progreso se pensaba ahora desde una óptica puritano-economicista donde la "emancipación" kantiana pasaba a un segundo término. ${ }^{3}$ Capitalismo, puritanismo y progresismo formaron una poderosa máquina cultural y social destinada a regurgitar la sustancia para ordenarla en una weltanschauung muy concreta, nada universal, un problema regional que no obstante se convertía en diseño global de la geopolítica del conocimiento occidental. ${ }^{4}$ El puritano espíritu asalariado del primer capitalismo suponía una continua relegación del goce en virtud de una recompensa que nunca llegaba. ${ }^{5} \mathrm{La}$ promesa capitalista se reforzaba con esta ideología del progreso; una suerte de exaltado mesianismo vuelto hacia el más allá (terrenal) que volvía a justificar el

\footnotetext{
2 NisBEt, Robert (1981): Historia de la idea de progreso. Barcelona: Gedisa.

3 Enmanuel KANT (1978): “QQué es la Ilustración” en Enmanuel Kant, Filosofia de la historia. México D.F.: Fondo de Cultura Económica.

${ }^{4}$ Walter Mignolo (2003): Historias locales/diseños globales. Madrid: Akal.

${ }^{5}$ Max WeBer (1973): La ética protestante y el espiritu del capitalismo. Barcelona: Península.
} 
sacrificio del presente en aras del futuro. El puritanismo protestante (en última instancia también el catolicismo) justificaban la rendición a la Ética del Trabajo y la transmutación de los campesinos y artesanos en, como diría poéticamente Marx, "apéndices de la maquinaria" industrial, en virtud a un juego chantajista del tipo castigo/recompensa. El progreso como idea, creencia y trascendencia dotaba al capital de una nueva mitología secular que abarcaba la empresa humana en la grandiosidad de los siglos, desde el lado secular pero en conjunción con el cristiano, ambos unificados y transversalizados por y en el capital, en una amalgama de moral cristiano-laborista y razón instrumental productivista.

Las primeras grandes subversiones en la sociedad industrial, los ludditas en las urbes y los swings en el campo, ${ }^{6}$ eran contrarios a las obligaciones que imponía esta mitología. Relativamente ajenos y sin lugar a dudas contrarios al funcionamiento de tal maquinaria abstracta pensaban en términos de presente, prefiriendo incendiar las máquinas que significaban su miseria antes que rendir pleitesía a la futurología tecnológica ${ }^{7}$. Aplacados los rebeldes contra el progreso por un ejército que superaba en número al que el estado había desplegado contra Napoleón y llamados al orden por los sindicatos recién legalizados, ${ }^{8}$ subyugados por los dispositivos panópticos y las leyes en torno a las workhouses y poorhouses, ${ }^{9}$ la discursividad del progreso comenzó a tornarse performativa. $\mathrm{Su}$ mitología fue utilizada con el fin de dotar de una legitimación ideológica al imperativo del capital-máquina, una vez derrocada su lucha antagonista en los 1830. Destruidas las resistencias, la idea de progreso se terminaría por volverse hegemónica en la segunda mitad del siglo, justo cuando el aumento de la producción y las reivindicaciones del movimiento obrero, después de décadas de miseria atroz, ofrecieron al menos alguna razón para ser un poco más optimista.

Esta mitología del progreso, en conjunción con el puritanismo y la cultura capitalística, terminó por configurar una weltanschuung dominada por el futuro económico y el determinismo tecnológico. Se volvería hegemónica en Inglaterra ya a mediados del siglo XIX. Desde los imperios occidentales, junto con el resto del paquete material-cultural capitalístico, se exportó este metarrelato al resto del planeta, reescribiendo la historia propia y ajena, ahora fortalecida esta retórica por

${ }^{6}$ Eric HoBSBAwn y George RuDÉ (1978): Revolución industrial y revuelta agraria. El capital Swing. Madrid: Siglo XXI.

${ }^{7}$ David NoBLE (2000): Una visión diferente del progreso, Barcelona: Alikornio.

${ }^{8}$ Leopold Roc (2003): "La domesticación industrial” en Selección de artículos de la revista Os cangaceiros. Logroño: Pepitas de calabaza.

${ }^{9}$ Zygmunt BAUMAN (1999): Trabajo, consumismo y nuevos pobres. Barcelona: Gedisa. 
su entrecruzamiento con las nuevas versiones evolucionistas que se importaban en bruto desde las ciencias naturales.

Las ideas evolucionistas habían sido ya enunciadas por progresistas como SaintSimon o Comte, y serán recogidas también por los movimientos revolucionarios a través del pensamiento de Marx y Engels. En la antropología serán desarrolladas a final de siglo por Morgan, Bachofen, Tylor et al. Inspirados por las teorías de darwinianas, estos antropólogos definirán la historia de la humanidad como un progreso de lo simple a lo complejo, de lo inferior a lo superior, de lo bruto a lo refinado, siempre lineal pero con etapas sucesivas prefiguradas; el salvajismo, la barbarie, la civilización. La historia se transformaba en evolución. La historia se encauzaba. Se convertía en un recorrido ferroviario, sujeto a raíles y con ciertas paradas determinadas; una proyección teleológica fatalmente determinada por la necesidad de la secuencia. Así, "la sociedad capitalista se petrifica -se reificacomo algo natural, como una 'segunda naturaleza"". ${ }^{10}$ Marx abrazó esta teleología. Para él capitalismo era una etapa necesaria (hasta que el propio capitalismo desarrolle los medios de producción y profundice sus propias contradicciones) para llegar a otro futuro paradisíaco, el socialismo, una estación final inevitable debido al juego dialéctico de la lucha de clases; un desenlace (el inicio de la "verdadera historia de la humanidad", el milenio secular) que no podía ser sino retardado o acelerado. ¿No se convertía así el marxismo, como diría Baudrillard, en el espejo de la producción capitalista, preso del sino, naturalizando, aunque fuese como etapa, la acumulación y expansión material y cultural del capital de un modo demasiado parecido al que hacían en su tiempo los liberales y hoy en día los neoliberales?

La idea del progreso como algo no sólo real sino inevitable se esgrimió en tiempos de la lucha contra las multitudes ludditas, pero triunfó después de ellos. Funcionaba culpabilizando a los masacrados por la máquina. Tal vez el mejor ejemplo de esta instrumentalización culpabilizante fue la representada por el creador de lo que se llamó la Organización Científica del Trabajo, Frederick Taylor. Taylor fue el resultado de todo un proyecto decimonónico de experimentación organizacional en el mundo fabril con el que se buscaba la disciplinamiento mecánico del cuerpo obrero. La suya era una mitología progresista, justo el reverso de la marxista, su imagen-espejo. En ella obreros y patrones navegan en un mismo barco, para buenaventura del Moloch industrial.

${ }^{10}$ Kevin RoBINS y Frank WeBSTER (2002): "El luddismo: la nueva tecnología y la crítica de la economía política" en Frank Manuel, Kevin Roberts, y Frank Webster, Máquina maldita. Contribuciones para una historia del luddismo. Barcelona: Alikornio, p. 85. 
Acusaba a cualquier trabajador "holgazán" de estar robando no ya a los patronos sino también a sus propios compañeros de trabajo: un obrero debía trabajar con diligencia y dando lo máximo de sí en nombre del progreso, que Taylor concebía casi como una instancia trascendente, una encarnación divina del bien común. En cierto sentido hoy en día la idea de progreso -llámese "modernización", llámese "desarrollo"- sigue funcionando de una forma muy parecida. De ahí la necesidad de retomar y continuar esta crítica. La mitología progresista sigue justificando la vieja máxima del fin justifica los medios, la miseria de hoy legitimada por una prometida (incluso ineludible) opulencia futura. El progresismo sigue exigiendo el sacrificio, hoy a través de las políticas neoliberales y sus "reajustes estructurales", de la misma manera que en la URRS Lenin y Stalin sacrificaron a la población bajo una similar coartada.

Una vez llegados hasta aquí, descrita la genealogía de la idea de progreso como un compromiso con unas determinadas formas de entender el mundo, este artículo pretende volver a pensar sobre el progreso y sobre "Occidente" a través de la comparación de distintos grupos humanos y tiempos históricos. Para ello, en un primer momento, volveré sobre uno de unos pilares fundamentales sobre los que se ha construido la idea de progreso: la aparición de la agricultura. La práctica agrícola suele ser entendida como un pilar fundamental pues es lo que hará posible la aparición del estado, las ciudades, el excedente, en definitiva, todo aquello que significa progreso o civilización. ¿Fue realmente un progreso el surgimiento de la agricultura? - En un segundo momento me volveré sobre la historia, sobre lo "occidental", lo "salvaje", lo "bárbaro" y lo "civilizado" con la intención de exponerlo a una breve deconstrucción.

El ser humano vivió durante el $99 \%$ de su historia de la recolección y de la caza. La agricultura no apareció hasta hace unos 12.000 años de forma precaria e incipiente en el Creciente Fértil. En la que posiblemente sea la primera ciudad de la historia, Çatal Höyuk, fundada hace unos 9.000 años en la península de Anatolia, las prácticas agrícolas eran tan precarias como subsidiarias. La mayoría de su alimento, a pesar de su sedentarismo, provenía de la caza y de la recolección. En América la agricultura no apareció hasta el 5000 a.C. Y tan sólo en cinco zonas se ha podido constatar que se haya desarrollado la producción de alimentos de forma original: en el Creciente Fértil, el Sureste chino, los Andes, Mesoamérica y en el 
Este de América del Norte. ${ }^{11}$ Según parece lo más probable, en el resto de los espacios la agricultura se desarrolló por imposición o por imitación. Por otra parte, el ser humano tuvo capacidad cognitiva y técnica desde hace decenas o cientos de miles de años para adoptar la agricultura. Es difícilmente sostenible que no se haya iniciado la producción agrícola durante este largo periodo de tiempo por el hecho de carecer de la idea de cómo hacerlo. Como señala Diamond, cualquier grupo humano que tenga una relación tan íntima con su entorno como la que tienen los grupos de cazadores-recolectores, capaz de acopiar registros de plantas y pautas ecológicas al nivel que lo hacían ellos, a un nivel tal que a veces rivaliza con los propios conocimientos de los etnobotánicos actuales, cualquier grupo humano así, debería saber cómo poder favorecer la reproducción de la especies vegetales. Al fin y al cabo, podemos constatar que no pocas de estas sociedades forrajeras utilizaban técnicas para aumentar la reproducción de ciertas plantas y árboles, como lo es la limpieza del terreno en torno a ciertos árboles frutales, con el fin de defenderlos de otras especies indeseadas y que compiten con estos árboles en su reproducción. Podemos constatar que conocían estas técnicas y las utilizaban pero aún así no decidían dar el salto a la vida agrícola. No se trataba de un asunto de carencia de know how, por tanto. Podemos afirmar con bastante seguridad que el ser humano vivió durante un inmenso periodo de tiempo sin querer sedentarizarse ni dedicarse a trabajar la tierra. Entonces la pregunta es por qué no surgió la agricultura antes, y también, por qué apareció en tan pocos lugares. ¿No deseaban todas esas gentes el progreso?

Marvin Harris ironizaba sobre la respuesta tradicional de corte progresista que solía darse con respecto a este dilema:

"Los cazadores-recolectores ocupaban todo su tiempo en la búsqueda de lo suficiente para comer. No podían producir un 'excedente más allá de la subsistencia' de modo que vivían en el límite de la extinción, padeciendo enfermedades crónicas y hambre. En consecuencia, era natural que desearan establecerse y vivir en aldeas permanentes, pero no se les ocurrió la idea de plantar semillas. Un día, un genio anónimo dejó caer unas simientes en un hoyo y muy pronto se iniciaron los cultivos en forma regular. La gente ya no tenía que trasladarse continuamente en busca de caza y el nuevo tiempo libre favoreció el pensamiento. Este hecho condujo a nuevos y más rápidos progresos en la tecnología y, por ende, a más alimentos -un 'excedente más allá de la subsistencia'-, lo que, finalmente, hizo posible que algunas

${ }^{11}$ Jared DiAmOND (1998): Gérmenes, armas y acero. Barcelona: Debate, pag. 109 
personas se apartaran de la agricultura y se convirtieran en artesanos, sacerdotes y gobernantes". 12

Este tipo de explicaciones, de las cuales cómicamente se mofaba Harris, se han visto desmentidas con los trabajos de las últimas cuatro décadas. Marshall Sahlins, uno de los principales disidentes de este paradigma explicativo, descubrió en esta argumentación el legado de una visión etnocéntrica y burguesa: al considerar al ser humano "primitivo" desde la óptica del ser humano moderno, al atribuirle los deseos y aspiraciones de éste y una tecnología precaria para saciar las necesidades que estos deseos y aspiraciones producen en la actualidad, se concluía que el hombre primitivo debía sentirse frustrado y miserable. En palabras de Sahlins: "habiéndole atribuido al cazador impulsos burgueses y herramientas paleolíticas juzgamos su situación desesperada por adelantado". ${ }^{13}$ Este mismo error de la antropología progresista había sido denunciado dos siglos antes por Rousseau al respecto de sus contemporáneos y antecesores. El ginebrino, muy especialmente en relación a Hobbes, advertía que "todos hablando sin cesar de necesidad, de avidez, de opresión, de deseos y de orgullo, han trasplantado al estado de naturaleza ideas que habían tomado en la sociedad; hablaban del hombre salvaje, pero dibujaban al hombre civil". ${ }^{14}$ De tal manera, siendo observable que en nuestras propias sociedades a pesar de los avances tecnológicos no somos capaces (por cuestiones políticas) de satisfacer las necesidades más básicas de una importante fracción de la población, ¿cómo los primitivos, dotados solamente de "un arco con unas flechas", podrían haberlo hecho? Tenían que ser pobres...

No obstante, la pobreza no tiene por qué guardar relación con el nivel tecnológico, por muy extraño que nos pueda parecer. La pobreza es una relación entre medios y fines; es una cuestión de deseo y carencia, es una cuestión también de representaciones culturales. Como decía Marx, una chabola al lado de una chabola no es riqueza ni pobreza, pero en el momento en que junto a la chabola se ubica un castillo, la chabola deviene pobreza.

La Economía Política es la ciencia de la escasez. La necesidad no es evidente por sí misma. Aun a pesar de las llamadas de lo biológico, la necesidad es siempre construida por el deseo. En palabras de Deleuze y Guattari, "la carencia es

\footnotetext{
12 Citado en Alcina Franch, José (1999): Evolución social. Madrid: Akal, pag. 107.

13 SAhlins, Marshall (1983): Economía de la Edad de Piedra. Madrid: Akal, pag.17.

14 Jean-Jacques RouSSEAU (1998): Discurso sobre el origen de la desigualdad entre los hombres y otros escritos. Madrid: Tecnos, pag. 119.
} 
preparada, organizada, en la producción social". ${ }^{15}$ Así, podemos decir que de lo que trata realmente la Economía Política es de "organizar la escasez, la carencia, en la abundancia de la producción, hacer que todo el deseo caiga en el gran miedo a carecer, hacer que el objeto dependa de una producción real que se supone exterior al deseo (las exigencias de la racionalidad), mientras que la producción del deseo pasa al fantasma". ${ }^{16}$ La economía olvida que el deseo no puede ser sino producción, como el elán de Bergson, y lo trata como si fuese carencia y como producto de algo ajeno: las necesidades. Pero, ¿acaso la carencia puede producir? ¿Acaso puede haber transformación y movimiento en la ausencia?

La Economía Política parte de un supuesto de necesidades infinitas para medios limitados y trata de cómo adecuarlos de la mejor manera. Pero, como señalaba Polanyi, no es evidente por sí mismo que haya necesidades infinitas ni medios limitados. Puede ocurrir lo contrario. Tenemos aire en abundancia que respirar, pero no de forma perentoria mucha necesidad de surcarlo con aviones. Realmente lo que ha hecho la economía capitalista es producir la carencia (atrapar el deseo en el fantasma). Sin embargo existe un camino zen, nos dirá Sahlins, para llegar a la riqueza: teniendo pocas necesidades; produciendo deseo y no carencia, dirían Deleuze y Guattari. Un camino parecido a éste puede ser el de distintos grupos cazadores-recolectores, por eso no deberíamos catalogarlos como pobres sino que, tal vez, como en su momento hizo Sahlins, es decir, como sociedades de la opulencia: sociedades de festín o carestía, pero carestía muy esporádica y asimilada como parte de la opulencia, una sociedad de prodigalidad a fin de cuentas. ${ }^{17}$

El capitalismo es una creación constante de carencias. Podría decirse que las crea de forma compulsiva, produciendo simulacros deseados. Toda adquisición de productos en el reino del capital suele ser al mismo tiempo una privación. De nuevo Sahlins:

"El sistema industrial y de mercado instituye la pobreza de una manera que no tiene parangón alguno y en un grado que hasta nuestros días no se había alcanzado ni aproximadamente. (...) el mercado pone a disposición de los consumidores un deslumbrante conjunto de productos: todas las cosas deseables al alcance de la mano pero nunca del todo al alcance de su mano. Lo que es peor, en este juego de libre elección del consumidor, cada adquisición es al mismo tiempo una privación, porque cada vez que se

15 Gilles Deleuze y Félix Guattari (2004): El Anti Edipo. Capitalismo y esquizofrenia. Barcelona: Paidós, pag. 35.

${ }^{16}$ Ibid.

${ }^{17}$ Marshall SAHLINS (1983): Economía de la Edad de Piedra. Madrid: Akal, pag. 14. 
compra algo se deja de lado otra cosa, en general poco menos deseable, e incluso más deseable en otros aspectos, que podríamos haber tenido en lugar de la otra. (...) La escasez es el juicio dictado por nuestra economía y, por lo tanto, también el axioma que dicta nuestra Economía". ${ }^{18}$

Pero, aunque el problema real efectivamente guarda relación con la producción sociocultural del deseo como carencia, va más allá de lo que escribía aquí Sahlins. Pues la privación -la carencia- no se construye sólo en la elección entre productos distintitos sino en el seno del propio producto. Lo que se compra nunca es el producto total que realmente se desea. Quien desea el "original" en el turismo sólo lo encontrará en la postal pues el lugar que simula es, muy posiblemente y como consecuencia de la conjunción del flujo capital-turismo, una simulación de la imagen publicitaria. La mayoría de las veces no deseamos un simple producto desnudo en su materialidad. Lo que deseamos es toda una puesta en escena a la que no tenemos un acceso en su totalidad. Deseamos mucho más que cierta materialidad: nadie desea simplemente un coche de cierta forma, color y potencia, sino todo un conjunto que lo rodea y se inscribe en él. Deseamos todos los valores, estatus y sensaciones con los que se agencia, pero la sensación de libertad después es frustrada por la realidad congestionada de los atascos o por el precio de la gasolina (y el trabajo que requiere para ser pagada; trabajo siempre como contraparte sacrificial del ocio, cuando no ocio como prolongación del trabajo). Aunque evidentemente no todo es tan terrible y en el consumo encontramos grandes dosis de gozo es también cierto que, en buena medida, la sociedad del espectáculo produce un volumen realmente alto de carencias y de deseos-carencia destinados a convertirse en escasez en tanto que o bien no tienen contraparte en lo real, que son simulacros y no se pueden materializar o bien solo se puede aspirar a sucedáneos, o bien están completamente fuera del alcance. Un volumen alto de carencia y escasez; alto en términos relativos. Alto, por ejemplo, en comparación con los grupos cazadores-recolectores que estaban escasamente tocados por la producción de carestía capitalística. Indudablemente, los grupos de cazadoresrecolectores eran más felices hace " $\mathrm{x}$ " décadas que, una vez incluidos por completo en el circuito capitalista, se convirtieron en obreros, amas de casa, alcohólicos y prostitutas. Los antropólogos o las organizaciones de apoyo a los pueblos indígenas como Survival pueden dar fe de esto. La "civilización" es muy probable que no sea un gran progreso para muchos de ellos.

Ahora bien, no quiere esto decir que entre los grupos forrajeros su deseo no produjese carencia -pobreza- ni tampoco que, al igual que a nosotros, los objetos

${ }^{18}$ Ibid, p. 16. 
no saciasen su apetito de forma demasiado efímera en muchos casos. Pero, según nos informaban los relatos etnográficos, la "carestía" se vivenciaba de otra manera con menos angustia si acaso. Entre los San, por ejemplo, las posesiones se guardaban caóticamente sin ninguna consideración ni preocuparse demasiado por conservarlas o si se rompían. Los Batek trocaban aparatos radiofónicos por piezas de caza y descuidaban su uso sin importarles mucho el que se estropeasen. Entre los Mbuti Turnbull observó que un hombre dejaba estropear a su hijo pequeño una pipa que acababa de fabricar. Alegaba que no le importaba demasiado ya que fácilmente podría reemplazarla. Los objetos construidos socialmente como necesidades podían ser repuestos sin demasiado esfuerzo, siempre había tiempo para ello, y el esfuerzo no era tan penoso como en nuestras jornadas de trabajo. Con el fin de conseguir otro más, y otro, desperdiciamos la mitad de nuestra vida de vigilia en largas jornadas en trabajos que no deseamos, incluso odiamos.

En términos de deseo-necesidad no sería justo decir que nosotros somos más ricos que las sociedades forrajeras. Pero es que, además, la lógica de los sistemas de dominación capitalista provoca que incluso las necesidades biológicas de subsistencia queden en muchos casos sin saciar. Suelen citarse apabullantes estadísticas de hambre y desnutrición en el mundo (800 millones de lo primero y unos 2.000 millones de personas desnutridas), y tal vez sean cifras exageradas, pero lo que parece cierto es que incluso en términos de subsistencia biológica el mundo de hoy es más pobre.

El reformador Tomás Moro se quejaba: "si vais a castigar definitivamente a los que de mayores cometen las infamias que ya desde la niñez se veía que iban a cometer (...) ¿qué otra cosa hacéis, pregunto, sino hacer ladrones, a los que luego vosotros mismos ejecutáis?" Ser mendigo, una consecuencia de la pobreza creada por las pautas de la dominación, era castigado con la pena capital en tiempos de Moro. En la sociedad actual ocurre algo de lo mismo con los emigrantes que mueren en las pateras o se dejan la piel en las cuchillas de la valla fronteriza. De nuevo las "víctimas" acaban siendo culpabilizadas: ¿Acaso no carecen de derecho a circular? ¿Por qué iban a tener derecho a la movilidad donde debe imperar el estriamiento de la soberanía estatal? El capital debe tener libertad de movimiento, las personas sólo el necesario para los fines de éste.

El hambre y la desnutrición hoy en día son un efecto político. Una condición inmanente al juego económico capitalista. El hambre y la desnutrición son una mera consecuencia de la dominación. Pero, ¿acaso fue esto siempre así? ¿Siempre ha existido explotación económica y dominación política? Bajo muchos regímenes agrícolas e industriales el hambre se ha constituido en una epidemia crónica. ¿Fue alguna vez de forma diferente? 
En 1960 un estudio sobre los aborígenes australianos realizado por McArhur y McCarty comenzó a desmentir otro de los mitos progresistas que dice que los avances tecnológicos acarrean necesariamente reducción de horas de trabajo y reducción de esfuerzos físicos. Haciendo un recuento del tiempo de "trabajo" de dos poblaciones aborígenes llegaron a la conclusión de que estas labores no les quitaban demasiado tiempo: dedicaban en total una media de entre 3 hs 45 min y 5 horas diarias a un conjunto de actividades diversas que abarcaban la caza, la recolección, la preparación de comida, la preparación y reparación de herramientas, la construcción y reparación de la exigua vivienda. No necesitaban invertir en todas estas tareas ni la mitad del tiempo que dedicamos nosotros al mero hecho de conseguir dinero (a parte debemos contabilizar todo ese tiempo que gastamos en comprar, arreglar la vivienda, limpiarla, vestirnos de la manera requerida para producir, desplazarnos al lugar de trabajo, etc.). Pudieron constatar también que estas actividades no eran para ellos ni una ardua labor ni nada frustrante. No las toman "como un trabajo desagradable que haya que completar cuanto antes sea posible, ni tampoco como un mal necesario que deba posponerse tanto como se pueda". ${ }^{19}$ Más aún, lo cierto es que no las tomaban como "trabajo" alguno. De hecho, no tenían palabras para diferenciar trabajo de juego, ni para diferenciar el trabajo como una actividad diferenciada en términos de "producción".

McArthur y McCarty obtuvieron estos datos a partir de una observación de una semana (en el campamento donde se "trabajaba" 5 horas) y dos semanas (en el de las $3 \mathrm{hs} 45 \mathrm{~min}$.). Una observación mucho más prolongada y minuciosa fue la efectuada por Richard B. Lee en el desierto del Kalahari. Sus resultados fueron aún más sorprendentes: los bosquimanos dedicaban a la caza y a la recolección una media diaria de 2 hs y 9 min los hombres y 2 hs y 10 min las mujeres. Las tesis que consideraban la vida primitiva como una vida al borde de la subsistencia, aquí, como en el caso australiano, eran negadas, precisamente para las poblaciones que se suponían más acuciadas por la subsistencia: los cazadores-recolectores que viven en zonas desérticas.

Los bosquimanos "trabajando" poco más de una media de dos horas al día (15 horas semanales) obtenían al día, contabiliza Lee, unas 200 calorías más de las que necesitaban y, aunque el $90 \%$ de su aporte calórico provenía del consumo de las nueces mondongo, comían una variedad de alimentos mucho mayor de la esperada. De hecho, no comían muchas especies animales y vegetales de las que aún así consideran comestibles. Y no lo hacían por el hecho de que a su paladar tenían peor gusto. Por último, Richard Lee rechazaba la hipótesis de "al borde de la

${ }^{19}$ Marshall SAHLINS (1983): Economía de la Edad de Piedra. Madrid: Akal, pag. 31. 
subsistencia" al percatarse de que cada año se pudrían en el suelo millones de nueces mondongo, como decía, su principal fuente de alimento. Definitivamente, dedicaban mucho menos tiempo que nosotros a labores de subsistencia (ni la tercera parte) por el simple hecho de que no querían y porque tampoco necesitan más. No ansiaban la maximización de "beneficios". Preferían organizar su vida para el placer, la ritualidad social y para el relax antes que para la acaparación. Su organización social era contraria al homo oeconomicus, como también era contraria a las formas del autoritarismo despóticas (según Silverbauer nada está peor visto que esto entre los San). En este sentido parece que no es del todo exagerado decir que la organización de su vida era más racional que la nuestra, a mucho menor "nivel" de "progreso".

Pero esto no sólo ocurre entre los cazadores-recolectores que aún persisten en las tierras desérticas, sino también en las zonas selváticas y los bosques. Los Hadza estudiados por Woodburn vivían en un terreno más fecundo. Según Woodburn, las gentes de esta tribu parecían mucho más preocupadas por los juegos de azar que por los azares de la caza. Dedicaban alrededor de un par de horas al día para la consecución de alimentos. ${ }^{20}$ Entre los Mbuti de la selva del Congo estudiados por Turnbull la realidad era parecida. Las fiestas entre ellos eran muy numerosas. Cuando daban caza a un elefante trasladaban el campamento a donde moría el animal y se pasaban una semana de fiesta continua sin preocupaciones. Cuando había alguna riña o disputa se convocaba el molimo (una fiesta tribal asamblearia para dirimir litigios) y una vez solucionados los problemas se realizaban fiestas exuberantes de comida que duraban toda la noche. El fin era devolverle la alegría al espíritu de la selva, al grupo también. Cualquier excusa valía para hacer una fiesta. ${ }^{21}$ La temporada de la miel, que dura un par de meses al año, era ya de por sí una fiesta continua, como también ocurre entre los Semang malayos, que de igual modo gustaban de este producto que la naturaleza les regalaba con prodigalidad. ${ }^{22}$

Los bosquimanos vivieron durante siglos rodeados de bantúes que practicaban el pastoreo y la agricultura pero nunca lo adoptaron. Esto a un progresista del viejo paradigma le podía parecer sorprendente. Richard Lee les preguntó el por qué, los bosquimanos le contestaron con otra pregunta: "¿para qué plantar cuando hay tantas nueces de mondongo en el mundo?" A los bosquimanos la agricultura les

20 James WoOdBuRn (1983): "Introducción a la ecología hazda." en Cultura y ecología en las sociedades primitivas. Barcelona: Mitre.

${ }^{21}$ Colin Turnbull (1984): Los pigmeos. El pueblo de la selva. Buenos Aires: Javier Vergara Ed.

22 George MuRDOCK (1945): Nuestros contemporáneos primitivos. México D.F.: Fondo de Cultura Económica. 
parecía algo inútil. A los Mbuti incluso algo despreciable. Ellos rechazaron por largo tiempo (y aún hoy algunos siguen rechazando) la agricultura y la "civilización": es demasiado dura, demasiado penosa. El trabajo agrícola es más duro y más aburrido, ¿si hay alimento suficiente para qué iban a querer adoptar estas prácticas?

Un error del viejo paradigma era partir de la base de que la agricultura además de reducir el tiempo de trabajo, algo que no es cierto, mejoraba también el nivel de vida, mejoraba la alimentación y la esperanza de vida. Pero esta hipótesis, complaciente con las teorías del progreso, también se ha visto desmentida. Como señala Livi Bacci, se ha podido constatar que con la adopción neolítica de la agricultura el nivel de vida bajó, las horas de trabajo aumentaron y la rentabilidad del mismo disminuyó. La alimentación se hizo más pobre y menos variada. La mortalidad aumentó debido a la precarización del alimento (reducido a unos pocos productos cultivados) y a las nuevas enfermedades, derivadas de la contaminación ambiental de la producción sedentaria y de las enfermedades provocadas por el contacto estrecho con los animales domesticados. Aún así, la agricultura sedentaria supuso un aumentó drástico de población al aumentar la fecundidad y la producción total de alimentos. Lo cierto es que en lo único en que la agricultura aventajaba a la caza-recolección es precisamente en que es capaz de alimentar a más población en un determinado terreno. Tiene otra segunda "ventaja": permite desarrollar con mucha más facilidad instituciones autoritarias que puedan crear y gestionar ejércitos más efectivos, más grandes y más disciplinados que las pequeñas hordas guerreras de los nómadas cazadores-recolectores. La agricultura favoreció la aparición del estado y la guerra, si bien solo allí donde las relaciones de poder se articularon de una manera muy concreta.

Es difícil defender que la adopción de la agricultura con respecto a la vida forrajera haya representado algún progreso, como tampoco representó ningún progreso la constitución de la "civilización" y su formación estatal. Desde sus inicios todo lo que cosechó fueron guerras, saqueos, epidemias y trabajos forzados para levantar templos en honor al déspota. El progreso es un mito complaciente con el estado de las cosas.

Hemos intentado argumentar que no es posible hablar de progreso a la hora de comparar las sociedades forrajeras conocidas con distintas sociedades agrarias (por lo demás, extremamente heterogéneas), que no es posible hacerlo ni en términos de deseo ni de bienestar material. Más aún, ni siquiera podemos hablar de un progreso económico comparando los grupos cazadoras-recolectoras con las sociedades agrarias, ni siquiera en comparación con las civilizaciones. Como decíamos, la pobreza es una construcción social relativa, "y como tal es un invento de la 
civilización. Ha crecido con la civilización, a la vez como una envidiosa distinción entre clases y fundamentalmente como una relación de dependencia que puede hacer a los agricultores más susceptibles a las catástrofes naturales que cualquier campamento o poblado de invierno de los esquimales de Alaska" ${ }^{23}$ Lo cierto es que, cuando Lee midió el tiempo de trabajo de los bosquimanos del Dobe se hallaban en una fuerte sequía, que había repercutido gravemente entre los bantúes pero había pasado casi desapercibida entre los bosquimanos.

\section{3}

Hablar de progreso es hablar de una sinrazón, y no sólo en cuanto a lo relativo a categorías nuestras tales como la "economía" o el "trabajo". En lo referente al arte, ¿podemos decir que existe en él progreso? ¿Kandinsky es mejor que Goya? ¿Está más avanzado o desarrollado Hendrix que Mozart o Joyce que Shakespeare? Cada cual tendrá su opinión y gusto al respecto. Y, qué decir de la ecología. Con la adopción de la agricultura de tala y quema la deforestación fue inmensa, y con la expansión del industrialismo hemos llegado en un nivel crítico. Qué decir de la felicidad, ¿somos más felices ante el televisor que alguien hace 10.000 años esculpiendo piedras? ¿Por qué? Tampoco existe progreso en cuanto a la libertad o la igualdad sexual: lo cierto es que las bandas de cazadores-recolectores suelen mostrarse mucho más igualitarias y menos antiautoritarias que las "tribus acéfalas", y estas tribus más que las primeras civilizaciones. Ni siquiera con la revolución feminista del siglo XX podemos decir con certeza que haya hoy menos patriarcado que en la sociedad mbuti, !kung o batek, en el caso de que el término "patriarcado" pueda ser utilizado para hablar de ellos y no sea necesario realmente utilizar un concepto distinto.

Solemos entender por progreso la mejoría en relación a nuestros propios valores morales y convicciones. Siempre que se habla de progreso se hace un saqueo hermenéutico del pasado desde una óptica etnocéntrica, un aplastamiento desde el juicio del presente, pero, como podemos ver, ni siquiera en nuestros propios términos existe un progreso muy claro. Esto no quiere decir que no haya habido grandes mejoras. Tal vez la más evidente de todas guarde relación con la medicina. En Europa, con la invención de las vacunas y la penicilina (además de las mejoras sanitarias y alimenticias) la esperanza de vida se duplicó con respecto a la de la Edad Media. Vivimos ahora mucho más de lo que podían vivir los cazadoresrecolectores sin medicina occidental. Aún así, la esperanza de vida de estos pueblos forrajeros tampoco era tan baja como se preveía. Según Lee, de los 287

\footnotetext{
${ }^{23}$ Marshall SAHLINS (1983): Economía de la Edad de Piedra. Madrid: Akal, pag. 53.
} 
bosquimanos estudiados una significativa proporción de la gente superaba los 60 años de edad (un 10\%), y el más anciano tenía entre 82 y 85 años. Una vez superada la niñez era normal vivir hasta los cincuenta y tantos años. Aquí también, en relación a la esperanza de vida, el progreso vuelve a verse desmentido: es probable que con la agricultura y la irrupción de la civilización la esperanza de vida disminuyese, al menos hasta la revolución científica. Claro que esto último también debemos decirlo sin hinchar demasiado el pecho: según el informe del PNUD del 2004 hoy en día en 24 países no se llega a los 50 años de esperanza media de vida y Mozambique, Sierra Leona y Ruanda no llega siquiera a los 40 años, que es un dato parecido al de la esperanza de vida medieval europea.

De todas maneras, no se critica aquí que la humanidad no haya conseguido mejoras en ciertos periodos de tiempo. Lo que se critica es ese discurso teleológico y occidentalista, que no pocas veces está detrás de las teorías del "desarrollo". Lo que también se critica es que haya cualquier linealidad para mejor o para peor a lo largo y ancho de la historia. Se critica cualquier aproximación teleológica definida en términos de progreso o de evolución social. La historia transcurre a veces con letargo, a veces con prolongaciones, en otras ocasiones a machetazos. La historia no avanza por etapas. La visión lineal del progreso, o suave y avanzante del evolucionismo aunque sea multilineal, es del todo inverosímil. La división de la historia por etapas que necesariamente se preceden y se suceden también. La historia no avanza sino que se atraganta, huye, corre, deja ir, deja estar.

Lo "civilizado", lo "salvaje" y lo "bárbaro" no tiene por qué ser interpretado de forma secuencial. En este sentido una interesante crítica a esta diferenciación por etapas, al clásico salvajes-bárbaros-civilizados, es el apuntado por Deleuze y Guattari en Mil mesetas. Con respecto a su anterior libro, el Anti Edipo, de su pensamiento en Mil mesetas dirán:

"la historia universal de la contingencia ganaba una mayor variedad. (...) En lugar de seguir, como en Anti Edipo, la sucesión tradicional salvajesbárbaros-civilizados, nos encontramos ahora frente a todo tipo de formaciones coexistentes: los grupos primitivos, que operan por series, y por evaluaciones "del último", en un extraño marginalismo; las comunidades despóticas, que constituyen, al contrario, conjuntos sometidos a procesos de centralización (aparatos de Estado); las máquinas de guerra, que no se apoderan de los Estados sin que éstos a su vez se apoderen de la máquina de guerra que no comportaban con anterioridad; los procesos de subjetivización que se ejercen desde los Aparatos de Estado y en los guerreros, la convergencia de estos procesos, en el capitalismo y en los Estados 
correspondientes; la modalidad de una acción revolucionaria; los factores comparados, según cada caso, del territorio, de la tierra y de la desterritorialización". 24

Subrayan el carácter no lineal de la historia. Hacen hincapié en cómo las tres grandes máquinas sociales -salvaje, despótica y capitalista- se yuxtaponen las unas a las otras, coexisten, pelean, se arañan, se sobrescriben, se atrapan, se entrecruzan los flujos. La máquina nómada o salvaje, cuyo cuerpo social está definido por la alianza y los linajes, es entendida como una combinación de "máquina de guerra" y "espacio liso" en contraposición con el espacio estriado del Estado. La máquina despótica, estriada, estatal, es definida como aquella cuyo cuerpo social está lleno por el significante del désposta-divinidad, que edipiza a través de esta sobrecodificación las alianzas y parentescos. Según la interpretación de Deleuze y Guattari, lo característico de los nómadas y "salvajes" sería la ausencia de estado y la codificación mediante la inscripción en los cuerpos (tatuajes, grafismos, figuras visuales, gestos, tonos sonoros, etc.). La "máquina despótica bárbara" estaría caracterizada por un espacio fuertemente estriado (un Estado férreo) y un sello imperial, cuyo mensaje está inscrito ya no en los cuerpos, sino en la figura del Déspota. La "máquina capitalista civilizada" sería aquella que ya no necesita codificar, ni en los cuerpos ni en la figura del déspota. No codifica ni sobrecodifica, sino que descodifica en flujos desterritorializados convertidos en axiomática económica; una axiomática que siempre permite la incorporación de un axioma añadido, flujo, capital como límite siempre desplazado. El capitalismo entendido como un límite que desterritorializa los planos de mercancías (mujeres, tierra, parentesco, etc.) bajo un traductor universal: el capital.

Así entendidas las tres máquinas sociales -salvaje, bárbara y civilizada- dejan de tener un orden secuencial, coexisten. La máquina salvaje coexiste con otra capitalística y con cierto cuerpo lleno de déspota. Efectivamente, no todo es capitalista en el capitalismo. Y en el despotismo agrario había mucho de capitalístico: monedas, comercio, plusvalías. Existen máquinas salvajes dentro de estructuras estatales y dentro de la realidad internacional capitalística (todas las que la antropología estudió) y también otras tribus con sus símbolos, ornamentaciones y rituales que marcan líneas de fuga (beatniks, hippies, anarquistas, comparsas carnavalescas, etc.) aún dentro o al lado de los flujos de la axiomática capitalista, tal vez edipizados por la figura despótica de un gobernante populista, etc. Nada de secuencias aquí sino rizomas, mesetas conectadas.

${ }^{24}$ Gilles Deleuze y Félix GuATtari (2004): "Prefacio a la edición italiana de Mil Mesetas", en Revista Archipiélago, nº17, octubre de 2004, Madrid, pag. 137. 
Lejos de la teleología progresista, la historia universal es la historia de la contingencia y no la de la determinación, la del deseo y no la de la necesidad, con cortes y límites que rompen la continuidad. ${ }^{25}$ Así, por ejemplo, a la pregunta de por qué Europa y no China u otros iniciaron el capitalismo no encontraremos la respuesta en razones de determinación tecnológica. No es la técnica lo que faltaba sino el deseo. Fue la confluencia de determinados flujos lo que construyó lo capitalístico en sistema: "Flujos descodificados. ¿Quién dirá el nombre de ese nuevo deseo? Flujo de propiedades que se venden, flujo de dinero que mana, flujo de producción y de medios de producción que se preparan en la sombra, flujo de trabajadores que se desterritorializan". ${ }^{26}$ Será preciso el encuentro de todos estos flujos, la contingencia de este encuentro, para que el viejo modelo muera y lo capitalístico emerja como instancia hegemónica. No hay determinación por el "progreso" ni de la técnica ni del conocimiento. Los propios griegos de la antigüedad conocían las técnicas para producir máquinas de vapor, pero no lo hicieron ni dieron comienzo a una revolución industrial. Su economía esclavista y sus filosofías producían distintos deseos. La historia universal es la historia de la contingencia y muchas veces también de la aleatoriedad, la del descubrir cosas por error, como Cristóbal Colón a propósito de su tropiezo con América, o los avances agrícolas a través de cálculos matemáticos que partían de una Tierra plana y un Sol que giraba a su alrededor, o la de tantos otros aciertos que hoy cometemos a partir de "evidencias" que mañana serán evidentemente falsas.

La historia no es ninguna línea recta que vaya ineludiblemente hacia ningún sitio, como algunos teóricos del cambio social han creído ver. La historia teje y desteje su lienzo como Penélope, avanza y retrocede dependiendo del viento, a venda-balazos, dibuja zig-zags, espirales, yuxtaposiciones. La historia está marcada por el poder y el deseo, encontronazos, desplazamientos distintos, vaivenes, marcas de emergencias que dirá Foucault, es decir, los puntos de entrada en escena de las distintas fuerzas. Es el escenario del combate del poder y el deseo. Tiras y aflojas. "La humanidad no progresa lentamente, de combate en combate, hasta una reciprocidad universal en la que las reglas sustituirán para siempre a la guerra"27 como le gustaría pensar a Kant. De hecho no progresa en absoluto; no en un

\footnotetext{
${ }^{25}$ Gilles Deleuze y Félix Guattari (2004): El Anti Edipo. Paidós: Barcelona, pag.145.

${ }^{26}$ Ibid, pag. 230 .

${ }^{27}$ Michel Foucault (1991): Microfísica del poder. Madrid: La piqueta, pag.17.
} 
sentido lineal. Lo único que es cierto, como he intentado señalar a propósito de las sociedades cazador-recolectoras y la coexistencia salvaje-bárbara-civilizada, es que la historia del progreso, evolucionista y capitalista, no es un relato verosímil, más bien esa una autojustificación occidentalista, muchas veces incluso supremacista.

La principal linealidad que ha trazado el pensamiento académico occidental es precisamente la de Occidente como unidad en progreso. Pero su propia identidad, la de la unidad que se quiere pensar como avanzante, es más que difusa. La evolución de Occidente se pretende dibujar desde mucho antes de que Occidente mismo se inventase, desde mucho antes de que nadie pensase el propio concepto: desde el tiempo de los griegos y los romanos. A través de un collage de política griega, derecho estatal romano, religión cristiana, ideología Moderna y derecho natural ilustrado se construye la linealidad de Occidente. Observamos hoy en nuestros países como un pensamiento supremacista, en virtud a tal interpretación histórica, pretende legitimar su supuesta superioridad frente a todo lo que es "ajeno" a él. Una suerte de xenofobia que lleva a autores como Samuel Huntington, ideólogo de estado al servicio de Bush, a definir lo occidental como lo exactamente opuesto al abominable Islam y a declarar la necesidad cultural de una guerra a muerte entre las "dos" civilizaciones; un nuevo revival del pensamiento histórico de la extrema derecha alemana, el mismo argumento que el que defendía Oswald Spengler (si bien éste considera a China como el antagonista). La idea del "choque de civilizaciones" de Huntington es simple: "o acabamos con ellos o acabarán ellos con nosotros". Pero puestos a trazar genealogías las cosas pueden resultar irónicas. ¿Quiénes son "ellos"? ¿Quiénes somos "nosotros"? De forma provocadora contestaría Fredy Perlman en Against His-Story, Against Leviathan!:

"Las caravanas mercantiles islámicas son la primera red extensiva de tentáculos de largo-alcance desde la derrota a manos de los macedonios del pulpo griego. Los musulmanes, y no los bizantinos, son los sucesores de los antiguos griegos. Y ellos lo sabían. Ellos tradujeron la mayoría de la filosofía, la literatura y la ciencia natural griega al árabe y al persa. Los cristianos occidentales descubrirían más tarde la herencia griega no en Grecia sino en la España musulmana, y tuvieron que aprender árabe para recuperar su herencia.

"Los mercaderes musulmanes, como los griegos, redujeron a las mujeres a esclavas domésticas. Se congregaban en el lugar del mercado. Discutieron todo desde la astronomía tolemaica hasta la filosofía aristotélica. Ellos eran conscientes del conflicto entre el racionalismo calculador exigido por sus tratantes y la piedad demandada por sus dioses (singular en el caso del Islam). Los griegos movieron sus actividades especulativas fuera del templo, al lugar del mercado; los musulmanes nunca habían tenido semejante templo. 
Los griegos redujeron sus lugares sagrados a ornamentos con los cuales cubrir sus tentáculos comerciales; los musulmanes recubrieron su tentáculos con ornamentos prestados de los romanos, los persas, los indios que los habían adquirido de los griegos". ${ }^{28}$

El mayor problema que tiene la teoría del "choque de civilizaciones" es definir precisamente cuáles son esas civilizaciones, tanto en sus orígenes, como en su genealogía histórica, como en su presente (¿es lo mismo el Islam del burka que el que profesan ciertos grupos de Malí donde las mujeres caminan por las calles con los pechos al aire? ¿Dentro de cincuenta años, cuando muy posiblemente la religión mayoritaria en Francia sea islámica, seguirá siendo Francia occidental?). Más problemático resulta cuando uno se para a leer el Corán y el Antiguo Testamento y se encuentra que son más o menos la misma cosa, al fin y al cabo Mahoma construyó su religión tomando mucho de el Antiguo Testamento y los Nuevos Evangelios. Arte, religión, política, derecho, arquitectura, tecnología, es muy difícil precisar dónde empieza el Islam y dónde Occidente, qué es de cada uno, pues lo cierto es que el mestizaje no es producto de la globalización actual sino que la globalización, a distintas velocidades e intensidades, lleva siglos, milenios, en curso.

Una de las grandes aportaciones de la antropología y la historia ha sido precisamente su contribución a la desmitificación de esa visión que consideraba posible definir "grupos culturalmente aislados", grupos con su propia deriva. Todo lo humano, mucho antes de la globalización, ya desde la prehistoria, se encuentra en continuo proceso de hibridación y mestizaje. La historia universal es la de la contaminación mutua; la de la continua supresión sensible de la pureza, que sólo puede existir en la historia en tanto que representación falsificadora. En ella los grupos devienen y se metamorfosean, redefiniéndose las fronteras conceptuales y los atributos de las sociedades y de las culturas, sin linealidad alguna, desplazando límites, construyendo y derribando murallas. La antropología del siglo XX pudo constatar la radicalidad de nuestra impureza: incluso los grupos de cazadoresrecolectores más aislados estuvieron siempre dentro de redes de trueque material e intercambio cultural. Y, por supuesto, hoy incluso los forrajeros más apartados están dentro de un sistema mundial capitalístico, con sus flujos de capital y weltanschauung girando en torno y dentro de ellos. ${ }^{29}$

\footnotetext{
${ }^{28}$ Fredy PerLman (1983): Against His-story, against Leviathan! Detroit: Red \& Black, pag. 137.

${ }^{29}$ Eric WOLF (1982): Europe and the people without history. Berkeley y California: University of Caligornia Press.
} 
Hemos estudiado comparativamente nuestra sociedad y las forrajeras y hemos criticado a través de esta comparación la idea del progreso. Hemos criticado el carácter teleológico, determinista y occidentalista de esta vieja idea ilustrada. Hemos puesto diversos ejemplos, podrían haberse señalado más. Podía haberse criticado igualmente otros distintos hitos de la ideología progresista: el industrialismo, sin ir más lejos, no fue en su momento un gran progreso. El dolor que causó su primera irrupción, dolor atroz que se extiende aún en la actualidad, escribió los relatos de Dickens y acompañado del imperialismo terminó por forjar las organizaciones sociales que dieron luz a Hitler y Stalin y dos guerras mundiales, entre otras cosas. Debiéramos recuperar la historia del luddismo para estudiarla con ojos más comprensivos.

Hemos traído a colación una redefinición del clásico salvajes-bárbaroscivilizados, intentando desmontar la linealidad y la pureza de estas categorías. Hemos querido criticar cualquier idea serial y de vía única. De esta manera, consideramos la historia como devenir y no como progreso. Nada permanece, todo cambia, pero nada tiene que avanzar por raíles determinados, ni siquiera tiene que avanzar en absoluto. Distintos grupos africanos o los aborígenes de la actual Suecia que hace unos milenios adoptaron la agricultura, la rechazaron más tarde, y después la volvieron a cultivar. El "progreso", al contrario de lo que dice el refrán popularizado, es evitable, es reversible. La historia es nómada; ella vagabundea, ella fuga, ella conquista, ella escapa.

Hay otro ejemplo más conocido de devenir contrario a la lógica pretendidamente sin retorno del progreso: la historia de la tribu más famosa de todas las habidas y por haber. Como señala Perlman en su contra-historia de la civilización, la historia de esta tribu fue el relato de una continua lucha por escaparse de las garras del Leviatán, que los convertía en esclavos, para volver a lo salvaje. El nombre del libro que recoge su historia de rechazo a la civilización es conocido por todos: La Biblia. Sus enemigos fueron las primeras civilizaciones despóticas. La civilización egipcia contra la que se levantó Moisés, y aquella otra que era heredera de la primera civilización sumeria, la "ramera Babilonia". La adopción de la civilización para esta tribu no significó progreso alguno sino esclavización. Una esclavización a la que en un primer momento -cuentan las escrituras- se entregaron voluntarios, pero de lo que no tardaron mucho en arrepentirse. Su lucha fue una lucha contra lo que aún hoy alguno llamaría "progreso", una lucha contra el estado, una lucha contra la civilización. Las múltiples y variopintas direcciones ulteriores que tomaron quienes se consideraban herederos del legado de esta tribu, que irguieron sus propios leviatanes en Roma y 
Jerusalén y contribuyeron a edificar otros tantos no menos despóticos, son un ejemplo más de las vueltas que da la historia, de lo paradójico de la misma, que se empeña por no seguir ninguna línea recta, ningún fatalismo, ningún infierno, ningún cielo

\section{BIBLIOGRAFÍA:}

AlCINA FRANCH, José (1999): Evolución social. Madrid: Akal.

BAUDRILLARD, Jean (2000): El espejo de la producción. Barcelona: Gedisa.

BAUMAN, Zygmunt (1999): Trabajo, consumismo y nuevos pobres. Barcelona: Gedisa.

Clastres, Pierre (1996): Investigaciones de antropología política. Barcelona: Gedisa.

Deleuze, Gilles y GuAtTari, Félix (2004): El Anti Edipo. Capitalismo y esquizofrenia. Barcelona: Paidós.

Deleuze, Gilles y GuAtTARI, Félix (2004): Mil mesetas. Capitalismo y esquizofrenia. Valencia: Pre-textos.

Deleuze, Gilles y GuAtTARI, Félix (2004): "Prefacio a la edición italiana de Mil Mesetas", en Revista Archipiélago, nº17, octubre de 2004, Madrid.

DiAMOND, Jared (1998): Gérmenes, armas y acero. Barcelona: Debate.

ENDICOTT, Kirk (1997): "Property, power and conflict among the batek of Malaysia." en Hunthers and gatherers. Property, Power and Ideology. Oxford: Berg.

FOUCAULT, Michel (1991): Microfisica del poder. Madrid: La piqueta.

HoBSBAwn, Eric; RudÉ, George (1978): Revolución industrial y revuelta agraria. El capital Swing. Madrid: Siglo XXI.

KANT, Enmanuel (1978): “QQué es la Ilustración” en Enmanuel Kant, Filosofía de la historia. México D.F.: Fondo de Cultura Económica.

LEE, Richard B. (1981): "La subsistencia de los bosquimanos !kung: un análisis de imputoutput.” en Antropología económica. Estudios etnográficos. Barcelona: Anagrama.

LIVI BACCI, Massimo (1990): Historia mínima de la población mundial. Barcelona: Ariel.

LöWY, Michael (2002): Walter Benjamin. Aviso de incendio. Buenos Aires: Fondo de Cultura Económica.

Manuel, Frank; Roberts, Kevin y Webster, Frank (2002): "El luddismo: la nueva tecnología y la crítica de la economía política” en Frank Manuel, Kevin Roberts, y Frank Webster, Máquina maldita. Contribuciones para una historia del luddismo. Barcelona: Alikornio, Barcelona: Alikornio.

Mignolo, Walter (2003): Historias locales/diseños globales. Madrid: Akal.

Moro, Tomás (1996): Utopía. Madrid: Tecnos.

MuRDOCK, George (1945): Nuestros contemporáneos primitivos. México D.F.: Fondo de Cultura Económica.

NiSBET, Robert (1981): Historia de la idea de progreso. Barcelona: Gedisa.

NoBle, David (2000): Una visión diferente del progreso. En defensa del luddismo. Barcelona: Alikornio.

Perlman, Fredy (1983): Against His-story, against Leviathan! Detroit: Red \& Black.

POLANYI, Karl (1989): La gran transformación: crítica del liberalismo económico. Madrid: La Piqueta. 
Roc, Leopold (2003): "La domesticación industrial” en Selección de artículos de la revista Os cangaceiros. Logroño: Pepitas de calabaza.

Rousseau, Jean-Jacques (1998): Discurso sobre el origen de la desigualdad entre los hombres y otros escritos. Madrid: Tecnos.

SAHLInS, Marshall (1983): Economía de la Edad de Piedra. Madrid: Akal.

SAHLINS, Marshall (1992.): Las sociedades tribales. Barcelona: Labor.

SERVICE, Elman R. (1973): Los cazadores. Barcelona: Labor.

SERVICE, Elman R. (1984): Los orígenes del Estado y de la civilización. Madrid: Alianza.

Silberbauer, George (1983): Cazadores del desierto. Cazadores y hábitat en el desierto del Kalahari. Barcelon: Mitre.

TuRnBull, Colin (1984): Los pigmeos. El pueblo de la selva. Buenos Aires: Javier Vergara Ed.

WeBer, Max (1973): La ética protestante y el espíritu del capitalismo. Barcelona: Península.

WOLF, Eric (1982): Europe and the people without history. Berkeley y California: University of Caligornia Press.

WoODBURN, James (1983): "Introducción a la ecología hazda." en Cultura y ecología en las sociedades primitivas. Barcelona: Mitre. 